\title{
Mutational and Kinetic Analysis of APE1 Endoribonuclease Activity
}

\author{
A. A. Kuznetsova ${ }^{a}$, A. A. Gavrilova ${ }^{a, b}$, D. S. Novopashina ${ }^{a}$, \\ O. S. Fedorova ${ }^{a, *}$, and N. A. Kuznetsov ${ }^{a, * *}$ \\ a Institute of Chemical Biology and Fundamental Medicine, Siberian Branch, Russian Academy of Sciences, \\ Novosibirsk, 630090 Russia \\ ${ }^{b}$ Novosibirsk National Research State University, Novosibirsk, 630090 Russia \\ *e-mail:fedorova@niboch.nsc.ru \\ **e-mail: nikita.kuznetsov@niboch.nsc.ru \\ Received September 14, 2020; revised November 9, 2020; accepted November 9, 2020
}

\begin{abstract}
Human apurinic/apyrimidinic endonuclease 1 (APE1) participates in the DNA repair system. It is believed that the main biological function of APE1 is $\mathrm{Mg}^{2+}$-dependent hydrolysis of AP-sites in DNA. On the base of structural data, kinetic studies, and mutation analysis, the key stages of APE1 interaction with damaged DNA were established. It has been shown recently that APE1 can act as an endoribonuclease that catalyzes mRNA hydrolysis at certain pyrimidine-purine sites and thus controls the level of certain transcripts. In addition, the presence of $\mathrm{Mg}^{2+}$ ions was shown to be not required for the endoribonuclease activity of APE1, in contrast to the AP-endonuclease activity. This indicates differences in mechanisms of APE1 catalysis on RNA and DNA substrates, but the reasons for these differences remain unclear. Here, the analysis of endoribonuclease hydrolysis of model RNA substrates with wild type APE1 enzyme and its mutant forms Y171F, R177F, R181A, D210N, N212A, T268D, M270A, and D308A, was performed. It was shown that mutation of Asn212, Asp210, and Tyr171 residues leads to the decrease of AP-endonuclease activity while endoribonuclease activity is retained. Also, T268D and M270A APE1 mutants lose specificity to pyrimidinepurine sequences. R177F and R181A did not show a significant decrease in enzyme activity, whereas D308A demonstrated a decrease of endoribonuclease activity.
\end{abstract}

Keywords: human apurine/apyrimidine endonuclease, APE1, endoribonuclease activity, active site, sitedirected mutagenesis, RNA substrates

DOI: $10.1134 / \mathrm{S} 0026893321020102$

\section{INTRODUCTION}

Human apurinic/apyrimidinic endonuclease APE1 is one of the enzymes involved in DNA base excision repair. The main biological function of APE1 is hydrolysis of the phosphodiester bond on the 5 '-side of apurinic/apyrimidinic sites (AP sites) resulting in the 5'-deoxyribose phosphate and 3'-OH groups at the ends of the chain breaking, which is necessary for the polymerase to incorporate an intact nucleotide. This is the AP endonuclease activity of APE1. However, in 2004, Gros et al. [1] found that the enzyme can recognize damaged nucleosides as substrates as well as AP sites, for example, the damaged nucleosides 5,6-dihydrouridine and $\alpha$-anomer of adenosine (nucleotide incision repair, NIR). APE1 also possesses 3'-phosphodiesterase, 3'-phosphatase [2], and $3^{\prime}-5$ '-exonuclease [3, 4] activities. Along with the repair activity, APE1 acts as a redox factor [5].

Abbreviations: $\mathrm{aPu}, 2$-aminopurine; BHQ1 (Black Hole Quencher-1), fluorescence quencher; F, 2-hydroxymethyl-3hydroxytetrahydrofuran; FAM, 6-carboxyfluorescein; CPy, pyrrolocytosine; NIR, nucleotide incision repair.
APE1 has been shown to cause degradation of the RNA strand in DNA-RNA duplexes (RNase H-like activity) [6], and can hydrolyze RNA containing an AP site [7], as well as structured undamaged mRNAs, for example, c-Myc mRNA, mainly at the UA, UG, and CA sites $[8,9]$. The ability to hydrolyze RNA was also shown with respect to microRNA, CD44 mRNA, and RNA components of the SARS coronavirus [10]. Barnes et al. [8] suggested that endoribonuclease hydrolysis of mRNA may be one of the functions of the APE1 cytoplasmic enzyme in the cell and found that, unlike the AP endonuclease activity, the endoribonuclease activity of APE1 does not require a metal ion. From this, it was concluded that APE1 utilizes different catalysis mechanisms for DNA and RNA substrates. Despite the intensive study of the functional features of the APE1 enzyme, it is still not known how the enzyme recognizes damaged 2'-deoxyribonucleotides and intact ribonucleotides that significantly differ in nature and structure.

According to X-ray structural data [11], the active site of the enzyme is formed by the amino acid residues Asp308, His309, Glu96, Asp210, Asp70, Tyr171, 
Asn212, and Asn174. In the complex of APE1 with DNA, the residues Arg73, Ala74, and Lys78 interact with three sequential phosphates on the DNA strand opposite to the AP site. The amino acid residues Tyr128 and Gly127 act as a wedge and expand the minor groove of the duplex. The residues Met270 and Arg 177 stabilize the non-helical position of the AP site. In this case, Met270 displaces the base opposite to the AP site, inserting into the minor groove of DNA, and Arg177 is inserted from the side of the major groove of DNA and forms a hydrogen bond with the phosphate group located on the 3'-side of the AP site. Coordination of the phosphate group located on the 5'-side of the AP site by the residues Asn174, Asn212, and His309 leads to the enzyme-substrate complex into a catalytically competent state. Asp70, Glu96, and Asp308 are involved in metal ion binding in the active site of APE1. Site-directed mutagenesis demonstrated [12] that the Asp219Ala substitution reduces both the DNA-binding and AP endonuclease activities of the enzyme, and substitution of residues Asp90, Glu96, and Asp308 with Ala led to a decrease in endonuclease activity while maintaining the DNAbinding activity. The residues Arg73, Ala74, and Lys78 are in contact with the phosphate groups of the complementary chain on the 5'-side of the AP site. The residues Tyr128 and Gly127 are positioned in the minor groove of DNA, which leads to its expansion by about $2 \AA$. The catalytic reaction begins with a nucleophilic attack by the oxygen atom of the water molecule coordinated directly or indirectly through the $\mathrm{Mg}^{2+}$ ion by the Asp210 residue $[11,13,14]$. Alternative mechanisms of catalysis have also been proposed [15]; according to which, the Tyr171 residue in the phenolate form interacts with the phosphate group being hydrolyzed or the His309 residue acts as a nucleophilic base.

Miroshnikova et al. demonstrated [14] that upon interaction of APE1 with a DNA substrate containing an $\mathrm{F}$ site, the nature of the divalent metal ion affects both DNA binding and catalytic hydrolysis of the 5 '-phosphodiester bond. Thus, $\mathrm{Cu}^{2+}$ ions completely inhibit DNA binding, probably due to the strong interaction of $\mathrm{Cu}^{2+}$ with the deoxyribose phosphate backbone of DNA. $\mathrm{Ca}^{2+}$ ions also inhibit the AP endonuclease activity of the enzyme, probably due to the incorrect location of the metal ion in the active site of the enzyme due to its larger ionic radius than $\mathrm{Mg}^{2+}$. Other ions reduce the enzymatic activity of APE1 in the following order: $\mathrm{Mg}^{2+}<\mathrm{Mn}^{2+}<\mathrm{Ni}^{2+}<\mathrm{Zn}^{2+}$. In addition, metal ions were found to affect both the ability of the enzyme to bind DNA and its structure [14].

Comparison of the AP endonuclease and endoribonuclease activities of APE1 reveals several differences. For the realization of the AP endonuclease activity of APE1 with DNA substrates, $\mathrm{Mg}^{2+}$ ions are required, while the presence of $\mathrm{Ca}^{2+}$ ions in the reaction mixture inhibits the enzyme. In the case of RNA substrates, APE1 works both in the absence of divalent metal ions and in the presence of calcium ions. In addition, Kim et al. showed [16] that upon hydrolysis of the phosphodiester bond in RNA sub-

strates $3^{\prime}-\mathrm{PO}_{4}^{2-}$ is formed as the final product of the reaction in contrast of DNA substrates hydrolysis resulting in $3^{\prime}-\mathrm{OH}$ group as the final product. Consequently, the mechanism of the hydrolysis reaction realized by APE1 on different types of substrates is different.

In the same work [16], the activity of various mutant forms of APE1 was studied, namely H309N, E96A [9], N68A, D70A, Y171F, D210N, F266A, D283N, D308A, and H309S. Comparative analysis of the activity of these mutant forms of APE1 with respect to model RNA and DNA substrates showed that most of the listed residues that are critical for hydrolysis of the AP site in DNA are also important for RNA hydrolysis, with the exception of the Asp283 residue, substitution of which led to the loss of only the AP endonuclease, but not endoribonuclease, activity.

However, it has not been established how APE1 recognizes undamaged ribonucleotides, how important the spatial structure of the substrate is, or which specific amino acid residues of the APE1 active site are involved in the recognition of the RNA substrate and catalytic hydrolysis of the phosphodiester bond.

We carried out a comparative analysis of the endoribonuclease hydrolysis of model RNA substrates by the wild-type APE1 enzyme and its mutant forms containing substitutions of the amino acid residues of the active site: Y171F, R177F, R181A, D210N, N212A, T268D, M270A, and D308A. For the first time, data were obtained on the binding of the mutant forms of APE1 to a model RNA substrate, as well as on the conformational transformations of the enzyme and RNA during the formation of the enzyme-substrate complex. These data allowed us to detail the role of the analyzed amino acid residues in the realization of the AP endonuclease, $3^{\prime}-5^{\prime}$ exonuclease, and endoribonuclease activity of APE1.

\section{EXPERIMENTAL}

Reagents. We used the following reagents manufactured by Sigma-Aldrich, USA: acrylamide, $N, N$-methylenebisacrylamide, 2-amino-2-(hydroxymethyl)-1,3-propanediol (Tris), tetramethylethylenediamine (TEMED), urea, boric acid, dithiothreitol (DTT), ethylenediaminetetraacetic acid (EDTA) and its sodium salt, Coomassie Brilliant Blue G-250, ammonium persulfate, 4-(2-hydroxyethyl)-1-piperazineethanesulfonic acid (HEPES), sodium dodecyl sulfate (SDS), magnesium chloride, potassium chloride, and glycerol. All solutions were prepared in double distilled water.

DNA and RNA substrates. Oligodeoxyribonucleotides were synthesized on an ASM-800 (Biosset, Russia) automatic DNA/RNA synthesizer using commercial amidophosphites of 2'-deoxyribonucleosides and 
Table 1. Model DNA and RNA substrates used

\begin{tabular}{|c|c|c|}
\hline Substrate & Sequence $^{\mathrm{a}}, 5^{\prime} \rightarrow 3^{\prime}$ & Structure \\
\hline $\mathrm{F} / \mathrm{G}$ & $\begin{array}{l}\text { FAM-d(GCTCAFGTACAGAGCTG)/ } \\
\text { BHQ1-d(CAGCTCTGTACGTGAGC) }\end{array}$ & 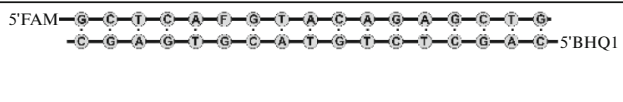 \\
\hline HP1 & FAM-r(AUAUAAGAUCAUUAUAU)-BHQ1' & $\begin{array}{l}\text { 5'FAM- } \overline{\mathrm{A}}-(\overline{\mathrm{U}}-\overline{\mathrm{A}}-\overline{\mathrm{U}}-(\overline{\mathrm{A}}-\overline{\mathrm{A}} \\
3^{\prime} \mathrm{BHQ} 1-\overline{\overline{\mathrm{U}}}-(\overline{\overline{\mathrm{A}}}-\overline{\overline{\mathrm{U}}}-\overline{\overline{\mathrm{A}}}-(\overline{\mathrm{U}})-\overline{\mathrm{U}}\end{array}$ \\
\hline HP2 & FAM-r(AUAUAACAUCAUUAUAU)-BHQ1 & 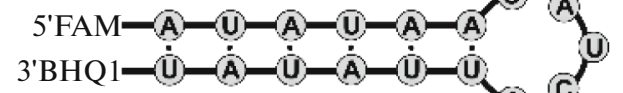 \\
\hline $\mathrm{HP} 1^{\text {Trp }}$ & r(AUAUAAGAUCAUUAUAU) & $\begin{array}{l}5^{\prime}-(\mathrm{A}-(\mathrm{U}-(\mathrm{A}-(\mathrm{U}) \\
3^{\prime}=\dot{(\mathbf{U}}-\dot{\mathrm{A}}-\dot{\mathrm{U}}-\dot{\overrightarrow{\mathrm{A}}}\end{array}$ \\
\hline $\mathrm{HP} 1^{\mathrm{C}-\mathrm{aPu}}$ & r(AUAUAAGAUC)-d(aPu)-r(UUAUAU) & \\
\hline $\mathrm{HP} 1^{\mathrm{aPu}-\mathrm{CA}}$ & r(AUAUAAGA)-d(aPu)-r(CAUUAUAU) & 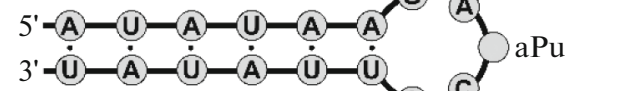 \\
\hline $\mathrm{HP} 1{ }^{\mathrm{CPy}-\mathrm{CA}}$ & r(AUAUAAGA)-d(C $\left.\mathrm{C}^{\mathrm{Py}}\right)-\mathrm{r}(\mathrm{CAUUAUAU})$ & 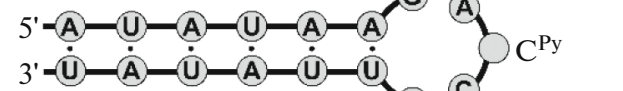 \\
\hline $\mathrm{HP} 1^{\mathrm{CA}-\mathrm{CPy}}$ & r(AUAUAGGAUCA)-d(C $\left.{ }^{\mathrm{Py}}\right)-r(U A U A U)$ & 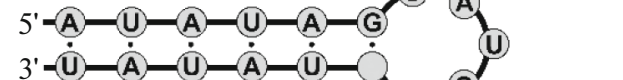 \\
\hline
\end{tabular}

F represents 2-hydroxymethyl-3-hydroxytetrahydrofurane; FAM represents 6-carboxyfluorescein; BHQ1 represent a fluorescence quencher; and aPu represents 2-aminopurine; $\mathrm{C}^{\mathrm{Py}}$, pyrrolocytosine.

CPG carriers (Glen Research, USA) (Table 1). The synthesized oligonucleotides were purified by HPLC on a PRP-X500 (Hamilton, Great Britain) ionexchange column, $12-30 \mu \mathrm{m}, 3.9 \times 300 \mathrm{~mm}$, and subsequent reversed-phase chromatography was carried out on a Bondapak C18 (Waters, Ireland) column, $15-20 \mu \mathrm{m}, 3.9 \times 300 \mathrm{~mm}$.

Oligoribonucleotides were prepared by the solidphase phosphoramidite method using the corresponding 2'-O-tert-butyldimethylsilyl (2'-O-TBDMS) ribonucleotide phosphoramidites (ChemGenes, United States). Fluorescein phosphoramidite (Glen Research) was used to incorporate fluorescein at the 5 '-end. To obtain oligonucleotides containing the fluorescence quencher BHQ1 (Black Hole Quencher-1) at the 3'-end, the corresponding modified polymer carrier 3'-BHQ-1 CPG (Glen Research) was used. Unblocking of oligoribonucleotides was performed under standard conditions. Unblocked oligoribonucleotides were isolated by preparative electrophoresis in $15 \%$ polyacrylamide gel ( $0.4 \mathrm{~mm}$ thick) under dena- turing conditions (acrylamide : $N, N^{\prime}$-methylenebisacrylamide $(30: 1), 8 \mathrm{M}$ urea, $50 \mathrm{mM}$ Tris $-\mathrm{H}_{3} \mathrm{BO}_{3}$, $\mathrm{pH} 8.3,0.1 \mathrm{mM}$ EDTA) at a voltage of $50 \mathrm{~W} / \mathrm{cm}$. The gel bands containing the product were excised and the oligoribonucleotides were eluted from the gel. Gel pieces were placed in a $2-\mathrm{mL}$ test tube, $1-1.5 \mathrm{~mL}$ of $0.3 \mathrm{M} \mathrm{LiClO}_{4}$ was added, and the mixture was kept on a thermomixer (Thermomixer Compact; Eppendorf, Germany) for $16 \mathrm{~h}$ at $25^{\circ} \mathrm{C}$ under shaking. Desalting of oligonucleotides was carried out on a C18 column (Waters, USA). The purity of oligonucleotides was checked using denaturing PAGE in a $15 \%$ gel followed by staining with Stains-all dye (Sigma-Aldrich).

The optical absorption of oligonucleotide solutions was measured on a NanoDrop 1000 (Thermo Fisher Scientific, United States) spectrophotometer. To calculate the concentration of oligonucleotides the molar absorption coefficient of oligoribonucleotides or their conjugates at $260 \mathrm{~nm}$ was used. The molar absorption coefficients of fluorescently labeled derivatives of oligoribonucleotides were considered equal to the sum of 
the molar absorption coefficients of oligonucleotides and the molar absorption coefficients of fluorescein and the quencher attached to the oligomer $\left(20900 \mathrm{M}^{-1} \mathrm{~cm}^{-1}\right.$ for FAM and $8000 \mathrm{M}^{-1} \mathrm{~cm}^{-1}$ for BHQ1).

Sequences of model DNA and RNA substrates are presented in Table 1.

Wild-type APE1 enzyme and its mutant forms. Wild-type APE1 enzyme was purified from the Escherichia coli Rosetta 2 cell line transformed with the pET11a plasmid carrying the human AP endonuclease gene according to the following procedure. The E. coli Rosetta 2 cell culture $(1 \mathrm{~L})$ was grown in LB medium containing $50 \mu \mathrm{g} / \mathrm{mL}$ ampicillin at $37^{\circ} \mathrm{C}$ until the optical density at $600 \mathrm{~nm}$ reached $0.6-0.7$ then shifted to $20^{\circ} \mathrm{C}$ and induced overnight with $0.2 \mathrm{mM}$ isopropyl$\beta$-D-thiogalactopyranoside. The cells were harvested by centrifugation (10 $\mathrm{min}$ at $4000 \mathrm{~g}$ ) and resuspended in $30 \mathrm{~mL}$ of buffer solution (RB1) containing $20 \mathrm{mM}$ HEPES-NaOH, pH 7.8, and $40 \mathrm{mM} \mathrm{NaCl}$. A French press was used to disrupt the cells. All subsequent procedures were carried out at $4^{\circ} \mathrm{C}$. The cell extract was centrifuged $(40 \mathrm{~min}$ at $40000 \mathrm{~g}$ ), then the supernatant was applied to a column I (30 mL, Q-Sepharose Fast Flow; Amersham Biosciences, Sweden) and washed with RB1. Fractions containing the APE1 protein were collected and applied to a column II (HiTrap-Heparin ${ }^{\mathrm{TM}}$; Amersham Biosciences). Chromatography was performed in RB1 buffer solution with a linear gradient of $40 \rightarrow 600 \mathrm{mM} \mathrm{NaCl}$; the optical absorption of the solution was recorded at a wavelength of $280 \mathrm{~nm}$. The purity of the APE1 protein was determined by SDS-PAGE. Fractions containing the APE1 protein were dialyzed in a buffer containing $20 \mathrm{mM}$ HEPES-NaOH, $\mathrm{pH}$ 7.5, $1 \mathrm{mM}$ EDTA, $1 \mathrm{mM}$ DTT, $250 \mathrm{mM} \mathrm{NaCl}, 50 \%$ glycerol, and stored at $-20^{\circ} \mathrm{C}$. The enzyme concentration was calculated from the value of the optical absorption of the protein at $280 \mathrm{~nm}$ and the coefficient of molar extinction $(\varepsilon)$ of $56818 \mathrm{M}^{-1} \mathrm{~cm}^{-1}$.

Mutant forms of APE1 containing the substitutions Y171F，R177F，R181A，D210N， N212A，T268D, M270A, and D308A were purified in the same way, except that the $E$. coli cells were transformed with expression vectors carrying the corresponding nucleotide substitutions, as described previously [17]. Mutant forms of APE1 containing the substitutions Y171F, R177F, and R181A were obtained for the first time and the corresponding mutations were introduced into the enzyme gene by site-directed mutagenesis (QuikChange XL; Stratagene, United States).

Hydrolysis of model DNA and RNA substrates. Analysis of the cleavage of the model DNA and RNA substrates was carried out according to the following procedure. To $10 \mu \mathrm{L}$ of the substrate solution, $10 \mu \mathrm{L}$ of the enzyme in RB2 buffer solution $(50 \mathrm{mM}$ Tris- $\mathrm{HCl}$ (pH 7.5), $50 \mathrm{mM} \mathrm{KCl,} 1 \mathrm{mM}$ EDTA, 1 mM DTT, 9\% glycerol at $25^{\circ} \mathrm{C}$ ) was added. In the case of DNA substrate, $2 \mu \mathrm{M}$ substrate and $0.05 \mu \mathrm{M}$ enzyme were used, while for RNA substrates, $2 \mu \mathrm{M}$ substrate and $4 \mu \mathrm{M}$ enzyme were added. To determine the effect of metal ions on the efficiency of hydrolysis of DNA and RNA substrates, $5 \mathrm{mM} \mathrm{MgCl}$ or $\mathrm{CaCl}_{2}$ were also added to the reaction mixture. After $30 \mathrm{~s}$ for the DNA substrate and after $1 \mathrm{~h}$ for the RNA substrates, the reaction was stopped by adding $20 \mu \mathrm{L}$ of a solution containing $9 \mathrm{M}$ urea and $25 \mathrm{mM}$ EDTA. PAGE was carried out in $20 \%$ gel under denaturing conditions (7 $\mathrm{M}$ urea) in a Protean II xi vertical temperature-controlled chamber (Bio-Rad Laboratories, Inc.) at a voltage of 200-300 V and a temperature of $55^{\circ} \mathrm{C}$. For visualization, the E-Box CX.5 TS gel documenting system (Vilber Lourman, France) was used.

Partial hydrolysis of HP1 and HP2 RNA substrates with RNase A was performed according to the following procedure. The reaction mixture $(20 \mu \mathrm{L})$ containing $3.0 \mu \mathrm{M}$ substrate and $3.0 \mathrm{nM}$ RNase A (SigmaAldrich) in RB3 buffer solution $(50 \mathrm{mM}$ Tris- $\mathrm{HCl}$ (pH 8.5), $50 \mathrm{mM} \mathrm{NaCl}, 1 \mathrm{mM}$ EDTA, $1 \mathrm{mM}$ DTT, $9 \%$ glycerol) was incubated for $5 \mathrm{~min}$ at $25^{\circ} \mathrm{C}$, and $20 \mu \mathrm{L}$ of a solution containing $9 \mathrm{M}$ urea and $25 \mathrm{mM}$ EDTA was added, then the mixture was incubated for $5 \mathrm{~min}$ at $96^{\circ} \mathrm{C}$.

Evaluation of the relative activity of APE1 mutant forms. The degree of substrate hydrolysis was determined using the Gel-Pro Analyzer 4.0 software package (Media Cybernetics, United States). The degree of hydrolysis was calculated as the ratio of the peak area of the hydrolysis product to the sum of the peak areas of the product and the uncleavaged oligoribonucleotide. The estimated error in determining the degree of modification, in general, did not exceed $20 \%$. The activity of the mutant forms was determined relative to the activity of the wild-type enzyme, which was taken as equal to 1 .

Microscopic thermophoresis (MT). The binding constants of the substrates with the APE1 enzyme were determined on a Monolith NT.115 device (NanoTemper Technologies, Germany) using standard capillaries (MonolithTM NT.115 Standard Treated Capillaries). Each point on the titration curves was obtained by measuring the fluorescence intensity of individual solutions $(10 \mu \mathrm{L})$ containing an oligonucleotide ligand $(1 \mu \mathrm{M})$ and an enzyme $(0.05-18 \mu \mathrm{M})$ in $\mathrm{RB} 2$ buffer solution at $25^{\circ} \mathrm{C}$. To calculate the values of the dissociation constants, the experimental data were fitted using the DynaFit software (BioKin, USA) [18] using the one-step binding model.

Stopped flow kinetics studies. A model SX.20 stopped-flow spectrometer (Applied Photophysics, UK) was used for registration of fluorescence intensity changes. The dead time of the instrument was $1 \mathrm{~ms}$. All experiments were carried out at $25^{\circ} \mathrm{C}$ in $\mathrm{RB} 2$ buffer solution. The excitation wavelength was $310 \mathrm{~nm}$ for the $\mathrm{aPu}$ and $344 \mathrm{~nm}$ for $\mathrm{C}^{\mathrm{Py}}$ fluorescent dyes, fluorescence emission was detected at $\lambda>370 \mathrm{~nm}$ using an LG-370 light filter. Trp fluorescence was excited at $290 \mathrm{~nm}$, fluorescence emission from enzyme Trp res- 

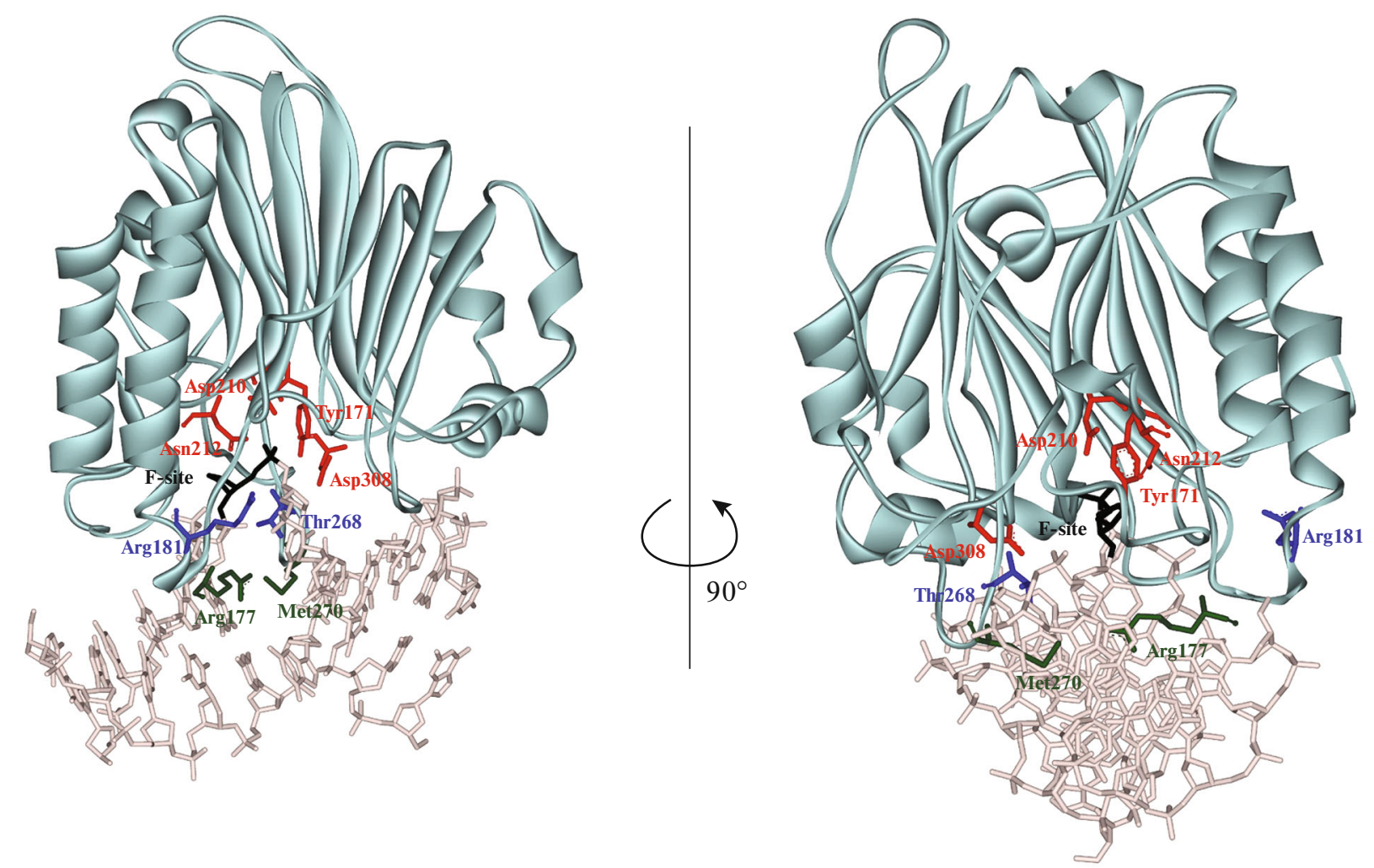

Fig. 1. The structure of the complex of the AP endonuclease APE1 with the F/G-substrate (PDBID 1DE8). Catalytic residues (Tyr171, Asp210, Asn212, and Asp308) are shown in red; residues that are inserted in the double helix after the target nucleotide is everted into the active site (Arg177 and Met270), in green; residues located in the substrate-binding site (Thr268 and Arg181), in blue; and the extra-helical position of the damaged nucleotide is highlighted in black.

idues was observed through a WG-320 light filter. The efficiency of fluorescence resonance energy transfer (FRET) within the FAM/BHQ1 pair was recorded with FAM excited at $494 \mathrm{~nm}$ and fluorescence emission at $\lambda>530 \mathrm{~nm}$ using an OG-515 light filter (Schott, Germany).

The concentration of APE1 in all experiments with Trp fluorescence detection was $2 \mu \mathrm{M}$, and concentration of RNA substrate was varied in the range of $0.5-$ $4.0 \mu \mathrm{M}$. The concentration of substrates containing $\mathrm{aPu}$ and $\mathrm{C}^{\mathrm{Py}}$ was $1 \mu \mathrm{M}$, and concentrations of APE1 in this case was $2 \mu \mathrm{M}$. Concentrations of reactants reported are those in the reaction chamber after mixing.

Typically, each kinetic curve shown is the average over at least four individual experiments.

The rate constant was calculated by fitting the kinetic curves according to equation (1):

$$
\mathrm{f}(t)=\mathrm{f}_{0}+\mathrm{f}_{1}\left(1-e^{-k_{\mathrm{obs}} t}\right)
$$

where $\mathrm{f}(t)$ is the observed fluorescence intensity at time $t ; \mathrm{f}_{0}$ is the background signal level; $\mathrm{f}_{1}$ is the maximum amplitude of the fluorescence intensity change at $t \rightarrow \infty ; k_{\text {obs }}$ is the observed rate constant. Under conditions of quasi-equilibrium and an excess of the substrate concentration with respect to the enzyme, $k_{\text {obs }}$ is described by equation (2):

$$
k_{\mathrm{obs}}=k_{1}[\mathrm{~S}]+k_{-1},
$$

where [S] is the concentration of the substrate, and $k_{1}$ and $k_{-1}$ are the rate constants of the formation and decay of the enzyme-substrate complex.

\section{RESULTS AND DISCUSSION}

\section{Selection of Amino Acid Residues of the APE1 Active Site to Study the Endoribonuclease Activity}

In order to identify the key amino acid residues of the enzyme active site responsible for the endoribonuclease activity of APE1, we studied the cleavage of model RNA substrates in the presence of wild-type APE1 and its mutant forms Y171F, R177F, R181A, D210N, N212A, T268D, M270A, and D308A. The amino acid residues selected for study (Fig. 1) can be divided into three groups: those involved in the catalytic reaction (Tyr171, Asp210, Asn212, and Asp308); those inserted in the double helix after the target nucleotide has been everted into the active site (Arg 177 and Met270); and those located in the substrate-binding site (Thr268 and Arg181). 
It should be noted that the participation of these residues in binding to DNA substrates containing a damaged nucleotide, the recognition of the F site, and the catalytic reaction has been previously established in several studies based on X-ray structure analysis and site-directed mutagenesis data. To sum up, Asp308 is involved in coordination of the $\mathrm{Mg}^{2+}$ ion in the active site, and its replacement with Ala leads to a decrease in the AP endonuclease activity [19]. Asn212 forms a hydrogen bond with the hydrolyzed phosphate group and also participates in the coordination of the water molecule and stabilization of the transition state. Its replacement with Ala results in a complete loss of endonuclease activity towards the AP site [19]. Asp210 coordinates the water molecule involved in the hydrolysis of the phosphodiester bond. Its replacement with Asn also leads to a complete loss of catalytic activity [20]. The Tyr171 residue either participates in the nucleophilic attack of the phosphate group in the phenolate form or stabilizes the transition state due to the formation of a hydrogen bond with the phosphate group [21, 22].

Met270 is thought to stabilize the non-helical position of the F site; at the same time, its replacement with Ala does not lead to a change in the enzyme activity [11]. Arg 177 is involved in specific binding of DNA containing the AP site [11].

Thr268 is located in the DNA-binding site. Its replacement with Asp leads to a significant decrease in the activity with respect to NIR substrates [23]. Arg 181 is located in the DNA-binding site and is involved in DNA binding.

\section{RNA Substrate Design}

According to the literature $[8,10]$, the main sites of RNA cleavage by APE1 are the dinucleotide sequences $\mathrm{CA}$, UA, and $\mathrm{UG}$ in single-stranded or weakly paired regions. Also, RNA cleavage has been observed at UC, CU, AC, and AU sites [10].

It can be assumed that both the pyrimidine-purine sequence and substrate structure are important for the formation of the catalytic complex, which can have a significant effect on the recognition of the target site. Indeed, in the works of Lee's group [8, 10], RNA cleavage was detected in single-stranded regions near the stems of hairpin structures, which may indicate a significant contribution of the RNA secondary structure to its recognition as a substrate of APE1.

We have previously analyzed the interaction of the APE1 with model RNA substrates of various structures [24]. We showed that the formation of a catalytically competent enzyme-substrate complex depends both on the conformational strain of the loop in the hairpin-shaped RNA-substrate and on the context and location of the phosphodiester bond to be hydrolyzed. Based on these data, we used two model RNA substrates, each 17 nucleotides long, which are short hairpin structures with a stem length of $6 \mathrm{bp}$ and loop size of 5 nucleotides. The HP1 substrate, FAM-r(AUAUAAGAAUCAUUAUAU)-BHQ1, contained one CA dinucleotide sequence in a loop, and the HP2 substrate, FAM-r(AUAUAACAUCAUUAUAU)-BHQ1, had two CA dinucleotide sequences (Table 1).

To analyze the kinetics of enzyme-substrate interaction, both $\mathrm{HP} 1^{\mathrm{Trp}}$ substrate with no fluorescent labels and the following substrates containing fluorescent labels were used: HP1, HP1 $1^{\mathrm{C}-\mathrm{aPu}}, \mathrm{HP} 1^{\mathrm{aPu}-\mathrm{CA}}$, $\mathrm{HP} 1^{\mathrm{CPy}-\mathrm{CA}}$, and HP1 $1^{\mathrm{CA}-\mathrm{CPy}}$. The HP $1^{\text {aPu-CA }}$ oligonucleotide contained a 2-aminopurine residue on the 3 '-side of the CA pair, while $\mathrm{HP} 1^{\mathrm{C}-\mathrm{aPu}}$ contained a 2-aminopurine residue immediately after cytosine. The HP1 ${ }^{\mathrm{CPy}-\mathrm{CA}}$ and HP1 $1^{\mathrm{CA}-\mathrm{CPy}}$ substrates contained a pyrollocytosine residue on the 3 '- and 5'-side of the CA pair, respectively.

\section{The Influence of Amino Acid Residue Substitutions on the Interaction of APE1 with DNA Containing F-Site}

To evaluate the activity of mutant forms of APE1, an $F / G$ substrate containing a 3-hydroxy-2hydroxymethyltetrahydrofuran residue (F-site) was used. The replacement of the catalytically significant amino acid residues Tyr171, Asp210, and Asn212, as well as Thr268 located in the DNA-binding site, leads to a significant decrease of the AP endonuclease activity (Fig. 2). At the same time, the replacement of Arg177 and Met270, which are inserted into DNA during the formation of a catalytically competent complex, as well as Arg181, which forms contact with the deoxyribose phosphate backbone in the DNA-binding site, insignificantly affects the efficiency of F-site hydrolysis. However, the replacement of Asp308, which is involved in the coordination of the $\mathrm{Mg}^{2+}$ ion in the active site, leads to a decrease in the activity by about $20 \%$ compared to the wild-type enzyme.

\section{Hydrolysis of RNA Substrates}

The influence of $\mathrm{Mg}^{2+}$ ions on substrate binding and hydrolysis of the phosphodiester bond in DNA are actively discussed [25-32]. Moreover, two catalytic mechanisms of APE1 action, involving either one or two $\mathrm{Mg}^{2+}$ cations, have already been proposed [11, 19]. At the same time, according to [10,24], APE1 cleaves RNA in the absence of divalent metal ions. Based on this data, we analyzed the interaction of wild-type APE1 and its mutant with model RNA substrates both in the absence of divalent metal ions (Fig. 3) and in the presence of $\mathrm{Ca}^{2+}$ (Fig. 4) and $\mathrm{Mg}^{2+}$ (Fig. 5) ions.

As shown in Fig. 3, in the absence of divalent metal ions in the case of both RNA substrates, HP1 and HP2, the reaction products accumulated; in this case, the cleavage occurred mainly at the CA sequence located in the loop. The presence of endoribonuclease 
(a)

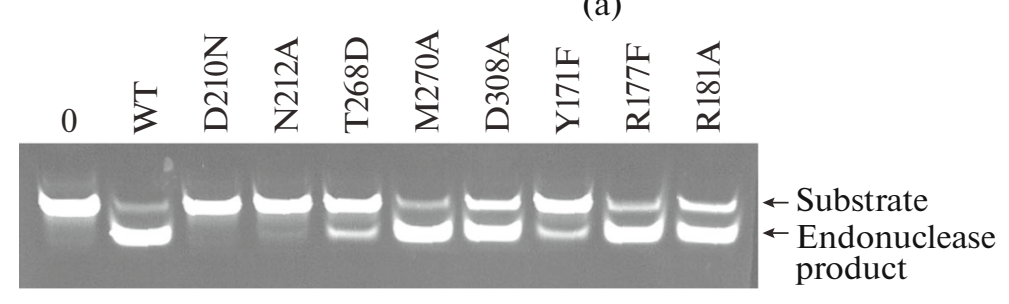

(b)

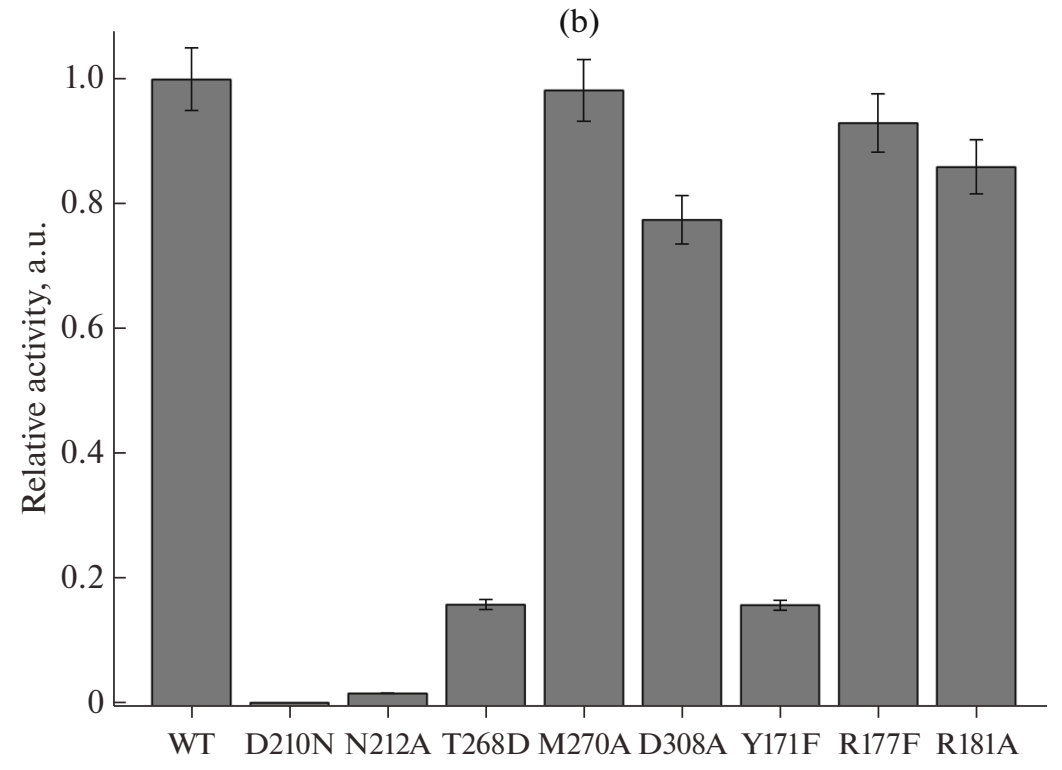

Fig. 2. Hydrolysis of the F/G-substrate by wild-type (WT) APE1 and its mutant forms. (a) Analysis of the reaction products by PAGE. (b) Relative activity of the F/G substrate hydrolysis by the wild-type enzyme and its mutant forms ([enzyme] $=0.05 \mu \mathrm{M}$, $\left.[\mathrm{F} / \mathrm{G}]=2.0 \mu \mathrm{M}, T=25^{\circ} \mathrm{C}, t=30 \mathrm{~s}\right)$.

reaction products in the case of mutant forms of the enzyme lacking AP endonuclease activity indicates the hydrolysis of the phosphodiester bond in RNA by a catalytic mechanism that differs from that at the AP sites of DNA.

Accumulation of endoribonuclease reaction products was also observed in the presence of $\mathrm{Ca}^{2+}$ ions (Fig. 4). As shown earlier [14], when APE1 interacts with a DNA substrate containing F-site, the presence of $\mathrm{Ca}^{2+}$ ions led to inhibition of the AP endonuclease reaction [33].

During the interaction of APE1 with RNA substrates in a buffer solution containing $5 \mathrm{mM} \mathrm{MgCl}_{2}$, which is required for the AP endonuclease activity, the products of both the endoribonuclease and $3^{\prime}-5^{\prime}$ exonuclease reactions were accumulated (cleavage of the quencher BHQ1 from the 3'-end) (Fig. 5). Presumably, the hydrolysis of the internucleotide phosphate group in the RNA substrate can proceed without the participation of the $\mathrm{Mg}^{2+}$ ion, while the hydrolysis of the 3'-terminal residue of BHQ1 proceeds according to the mechanism typical for DNA hydrolysis substrates. This conclusion is also supported by the absence of products of 3 '-5'-exonuclease degradation of RNA substrates under the action of mutant forms that lack AP endonuclease activity (D210N, N212A, T268D, Y171F).

We calculated the relative activity of all APE1 mutant forms regarding to RNA substrates HP1 and HP2 in the presence of EDTA and divalent metal ions $\mathrm{Mg}^{2+}$ and $\mathrm{Ca}^{2+}$ (Fig. 6).

It is interesting to note that the substitutions D210N and N212A, which lead to the disappearance of AP endonuclease activity, did not block the endoribonuclease activity of APE1. Both residues, Asn212 and Asp210, coordinate the water molecule in the active site, which acts as a nucleophile in the catalytic hydrolysis of DNA. Thus, it can be assumed that RNA cleavage depends on the presence of Asn212 or Asp210 to a much lesser extent than in the case of DNA substrate, which means that the alternative catalytic mechanism is involved in the hydrolysis of RNA substrates by APE1. Also, the replacement of another key catalytic residue, which is necessary for the effective realization of the AP endonuclease activity, Tyr 171 did not lead to a decrease in the efficiency of hydrolysis of RNA substrates. 
(a)

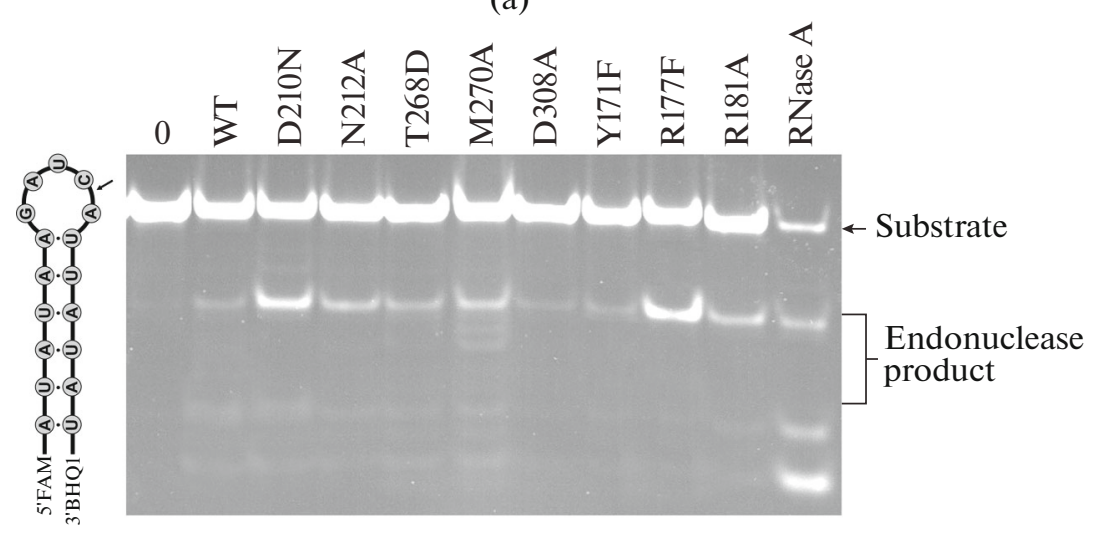

(b)

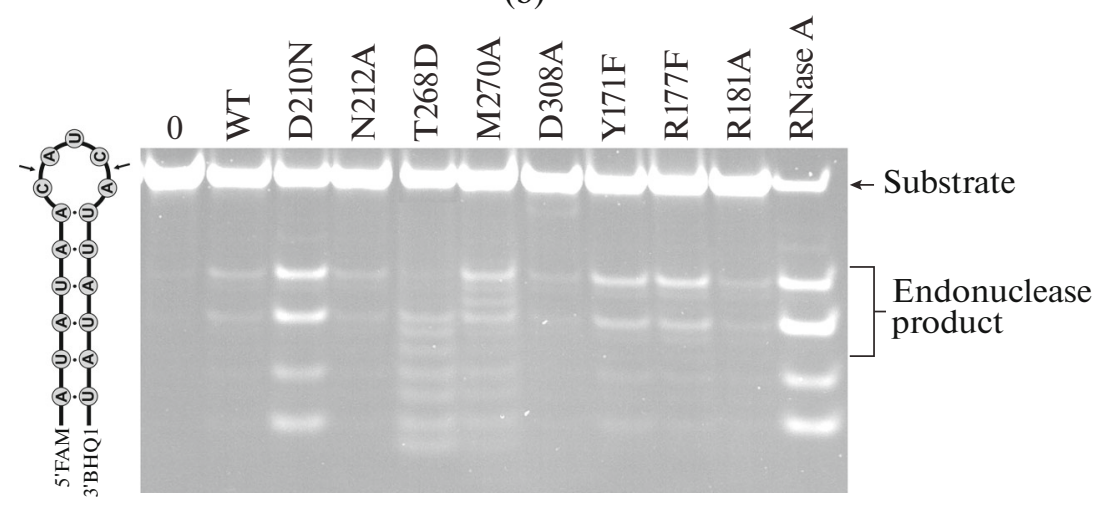

Fig. 3. Hydrolysis of (a) HP1 and (b) HP2 by wild-type (WT) APE1 and its mutant forms in the presence of 1 mM EDTA. $[$ APE1 $]=2.0 \mu \mathrm{M},[\mathrm{RNA}]=1.0 \mu \mathrm{M}, T=25^{\circ} \mathrm{C}, t=1 \mathrm{~h}$.

The T268D substitution has a significant effect (an approximately 5-fold decrease in activity compared to WT, Fig. 2b) on AP endonuclease activity. Indeed, the T268D substitution can disrupt the interactions of APE1 with DNA through electrostatic repulsion in the DNA-binding site, since the Thr268 residue is located in a loop that is inserted into the minor groove near the AP site. In this case, the Thr268 side group is located between the side chain of Met270, which is inserted into the DNA in place of the F-site, and the phosphate group of the DNA substrate. Therefore, aspartate at position 268 can prevent substrate binding through steric interactions with the Met270 side chain. It is interesting to note that substitutions T268D and M270A in APE1 lead to a loss of specificity of the enzyme for the pyrimidine-purine sequence in RNA substrate compared to the wild-type enzyme (Figs. 3-5). This loss of specificity for the RNA substrate context indicates that the effect of the T268D substitution cannot be due to electrostatic repulsion alone. Presumably, the effect of this substitution, on the one hand, is associated with the interaction of Thr268 with the side chain of Met270, which is inserted into the void formed after the target nucleotide is everted into the active site of the enzyme. On the other hand, the M270A substitution should theoretically reduce any steric hindrance in the binding of APE1 to both DNA and RNA substrates and, therefore, the activity of the M270A mutant form is practically indistinguishable from that of the wild-type enzyme.

Indeed, substitution of Met270 did not reduce the ability of APE1 to cleave AP sites, from which we can conclude that this residue is not involved in the process of nucleotide eversion into the active site of the enzyme. Thus, the function of Met270 is most likely to stabilize the state in which the hydrolyzed nucleotide is everted and located in the active site. The loss of specificity for the CA sequence also indicates that Met270 plays an important role in target nucleotide recognition. As for the replacement of the Arg 177 residue, which is inserted into the major groove, and the Arg181 residue located in the DNA-binding site, they had almost no affect either the AP endonuclease or endoribonuclease activity.

The AP endonuclease activity of the D308A APE1 mutant was similar to that of the wild-type enzyme but decreased upon hydrolysis of RNA substrates. The coordination of the $\mathrm{Mg}^{2+}$ ion with the Asp308 residue can be important for stabilizing network contacts in the catalytic site during DNA cleavage. In addition, the Asp308 residue stabilizes the position of the His309 residue, which forms contact with the phosphate group of the hydrolyzed nucleotide, thereby 
(a)

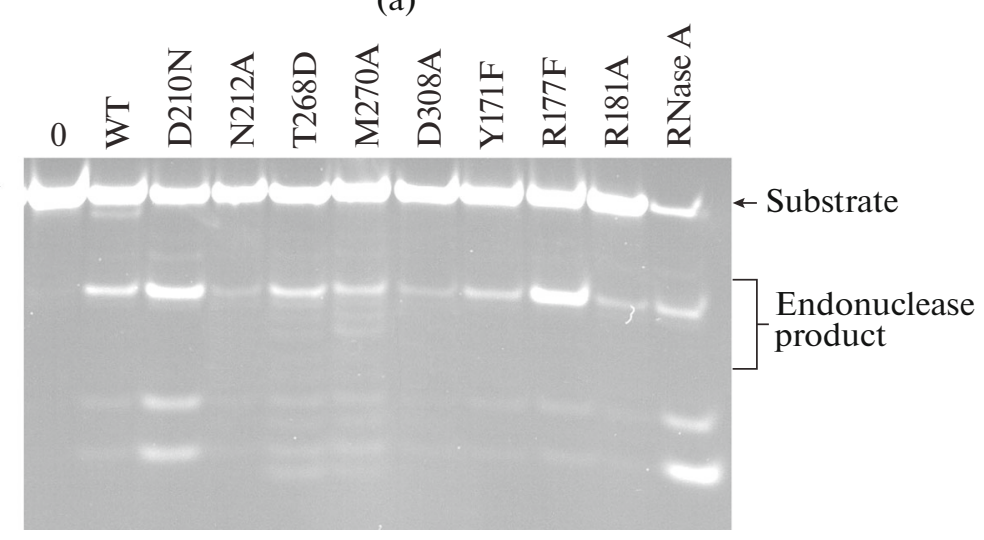

(b)

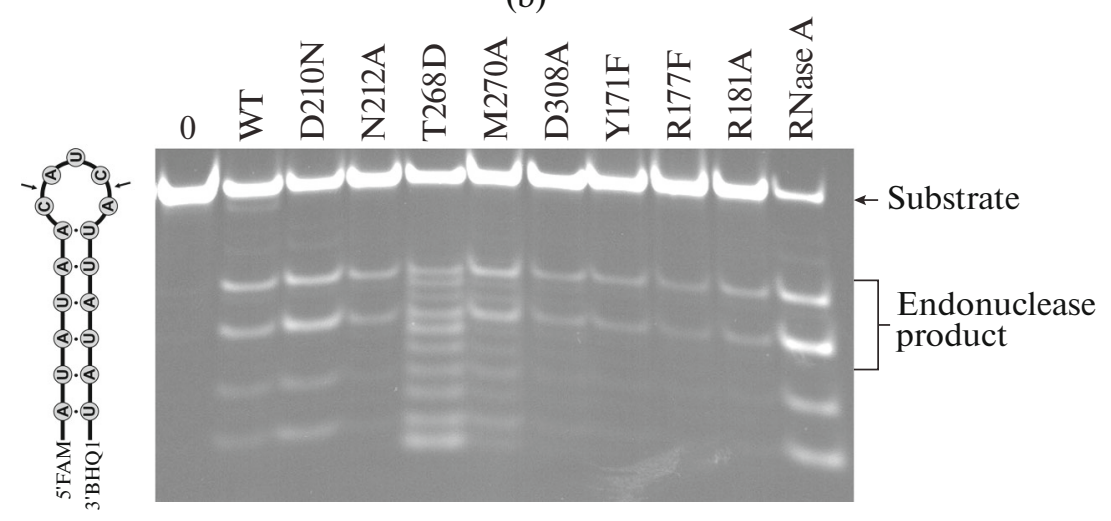

Fig. 4. Hydrolysis of the RNA substrates HP1 (a) and HP2 (b) by wild-type (WT) APE1 and its mutants in the presence of $5 \mathrm{mM}$ $\mathrm{CaCl}_{2} \cdot[\mathrm{APE} 1]=2.0 \mu \mathrm{M},[\mathrm{RNA}]=1.0 \mu \mathrm{M}, T=25^{\circ} \mathrm{C}, t=1 \mathrm{~h}$.

(a)

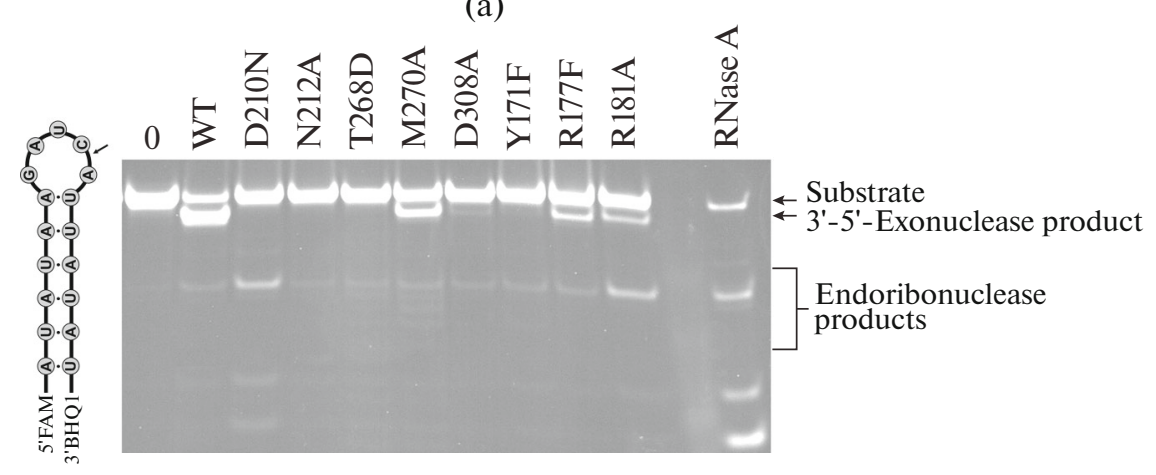

(b)

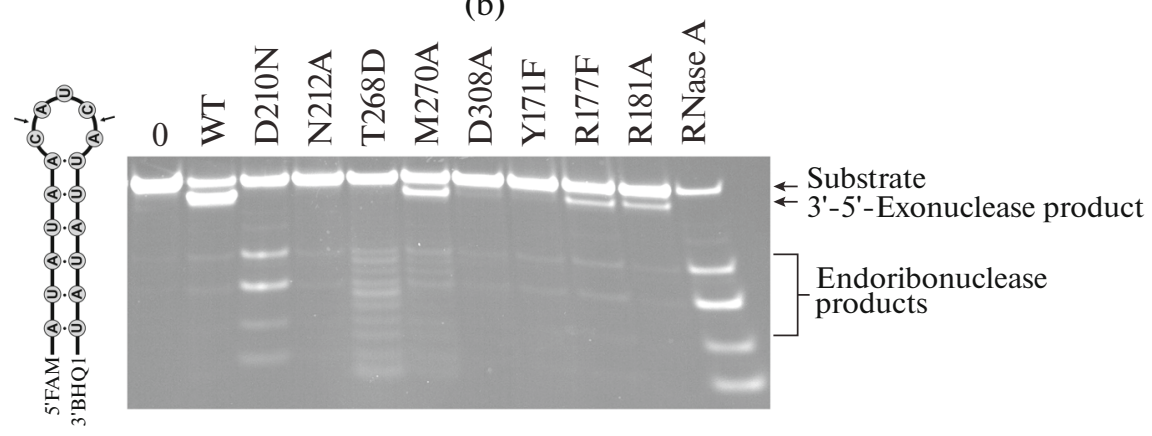

Fig. 5. Hydrolysis of the RNA substrates HP1 (a) and HP2 (b) by wild-type (WT) APE1 and its mutants in the presence of $5 \mathrm{mM}$ $\mathrm{MgCl}_{2}$. [APE1] $=2.0 \mu \mathrm{M},[\mathrm{RNA}]=1.0 \mu \mathrm{M}, T=25^{\circ} \mathrm{C}, t=1 \mathrm{~h}$. 

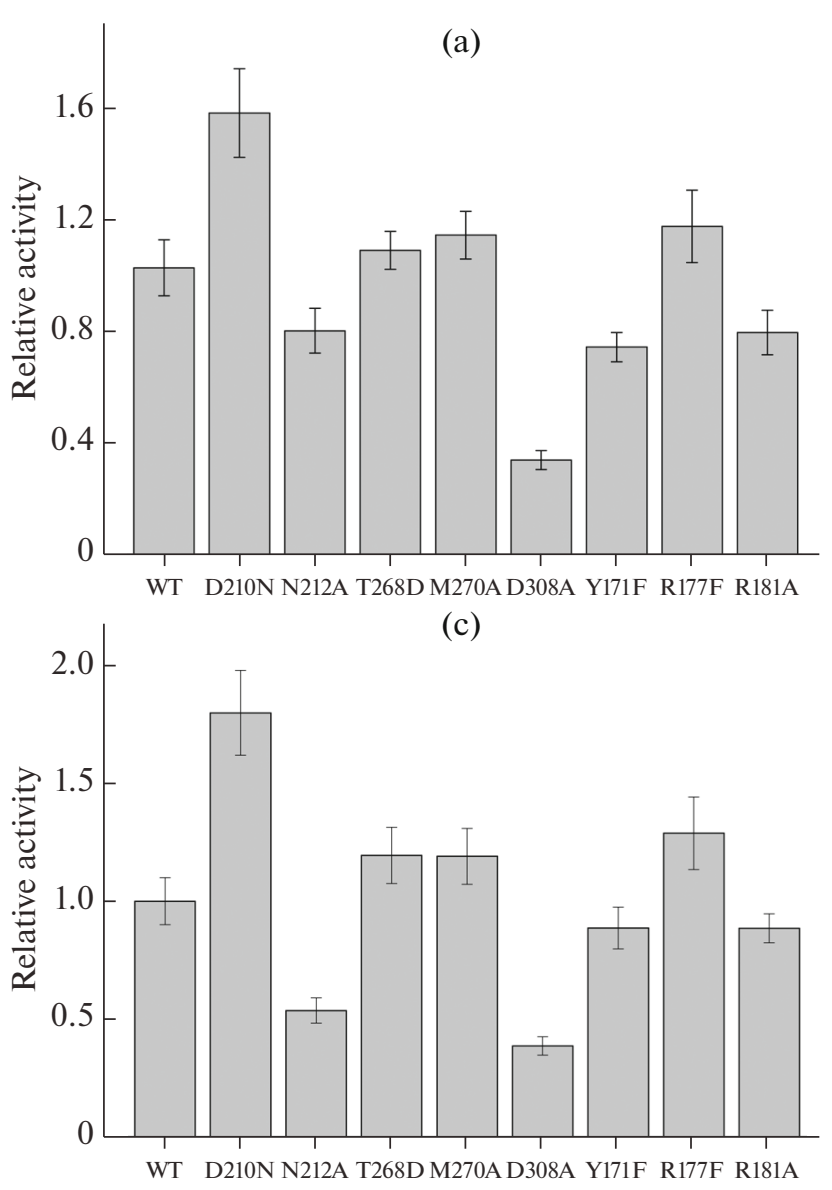

(e)

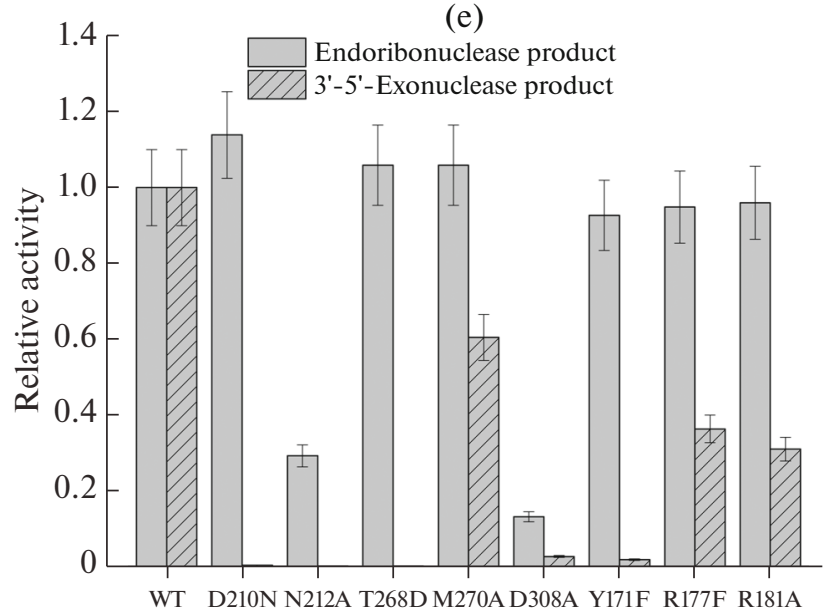

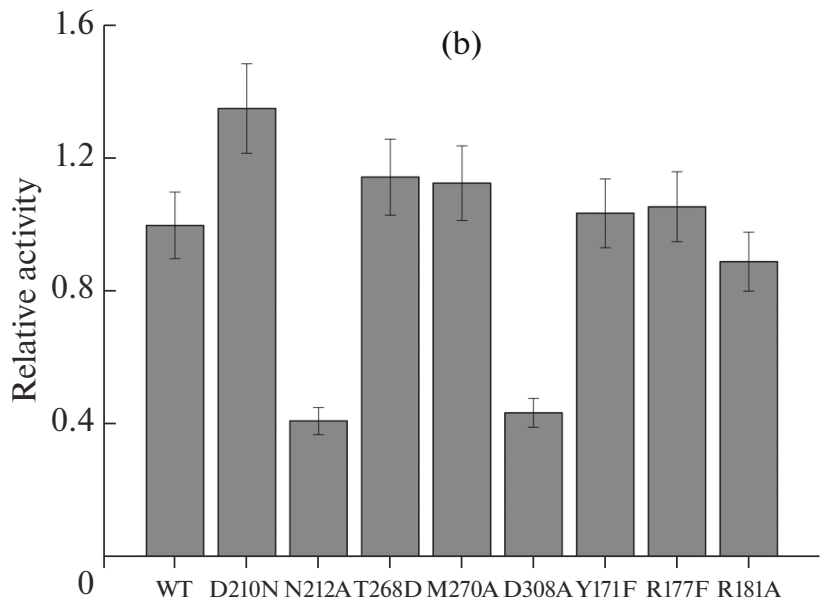

(d)

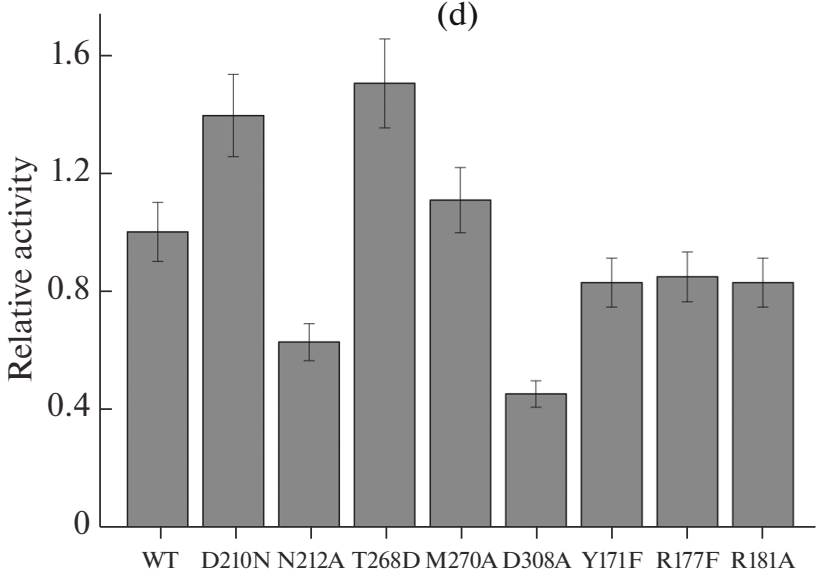

(f)

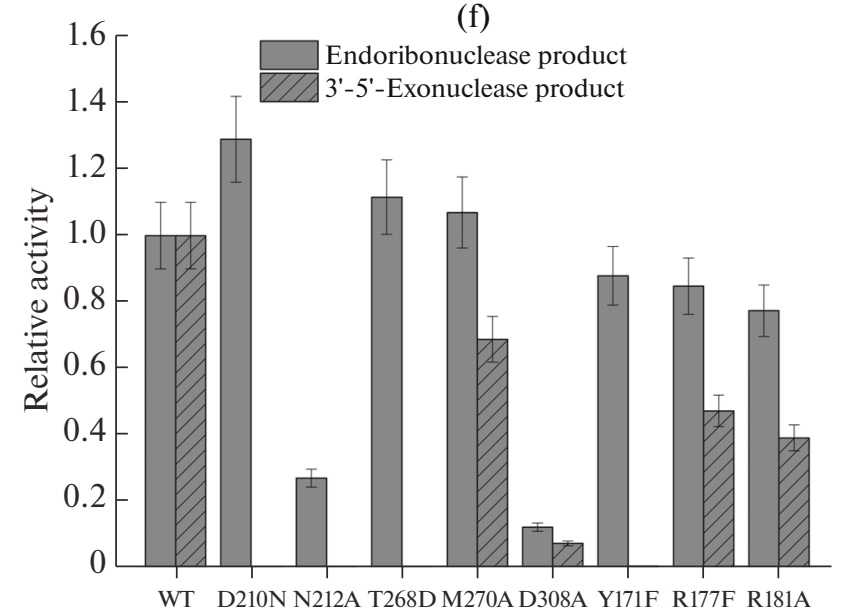

Fig. 6. Relative activity of wild-type and mutant APE1 in the hydrolysis of the HP1 (a, c, e) and HP2 (b, d, f) substrates in the presence of $1.0 \mathrm{mM} \operatorname{EDTA}(\mathrm{a}, \mathrm{b}), 5.0 \mathrm{mM} \mathrm{CaCl}_{2}(\mathrm{c}, \mathrm{d})$, and $5.0 \mathrm{mM} \mathrm{MgCl} 2$ (e, f).

contributing to the achievement of the catalytically competent state of the enzyme.

\section{Binding of RNA Substrates}

Using microscopic thermophoresis (MT), the binding of wild-type APE1 and its mutant forms to the HP2 substrate was studied (Fig. 7a). The dissociation constants $\left(K_{\mathrm{d}}\right)$ of enzyme-substrate complexes were calculated from the titration curves (Fig. 7b). It was shown that complex formation of APE1 with HP2 was characterized by close values of the dissociation constants. Thus, none of the analyzed mutations led to serious decline of enzyme-substrate interactions. Moreover, the lowest $K_{\mathrm{d}}$ value $(0.6 \pm 0.1 \mu \mathrm{M})$ was obtained for D210N APE1, which is in good agree- 

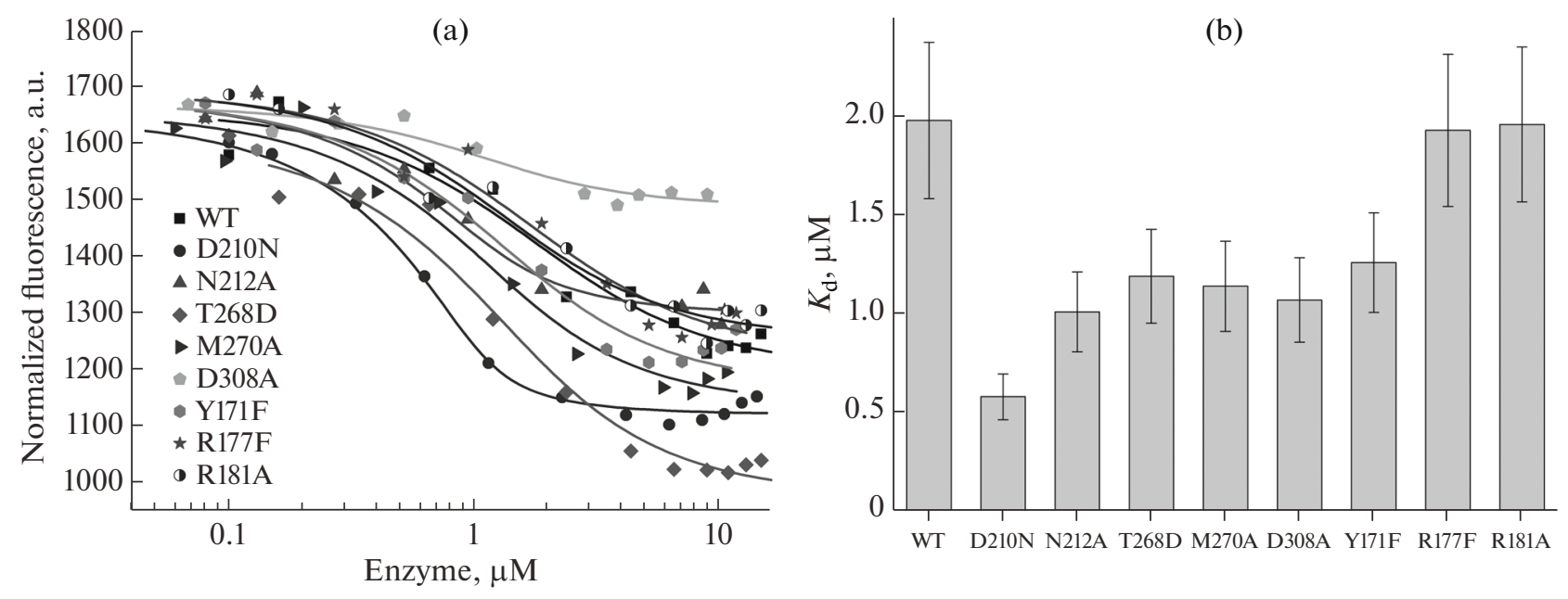

Fig. 7. Determination of the dissociation constants $\left(K_{\mathrm{d}}\right)$ of enzyme-substrate complexes by microscopic thermophoresis using HP2 as a substrate. (a) Titration curves of the HP2 substrate under the effect of the wild-type (WT) and mutant APE1 forms. (b) Comparative analysis of the dissociation constants of the APE1-HP2 complexes.

ment with the literature on the stronger binding of this mutant to model DNA substrates as than the wildtype enzyme [17, 20, 30,34]. At the same time, the D210N APE1 exhibited increased activity with respect to both studied RNA substrates both in the absence and in the presence of divalent metal ions. In addition, the two least active mutant forms of APE1, D308A and N212A, also bound the RNA substrate more efficiently than the wild-type enzyme. Thus, the differences in the activity of mutant APE1 forms are most likely associated with the influence of the studied amino acid residues on the formation of a catalytically competent state, and not on the stage of the enzymesubstrate complex formation.

\section{Analysis of the Kinetics of the Interaction of Wild-Type APE1 with the HP1 RNA Substrate}

In our earlier studies [33, 35], the kinetic analysis of the binding and hydrolysis of AP site by APE1 under pre-steady state conditions has been performed. In the present work the changes in fluorescence intensity of Trp residues of APE1 during endoribonuclease reaction were registered at times less than $0.5 \mathrm{~s}$, which most likely correspond to the formation of an enzyme-substrate complex (Fig. 8a). Notably, the slow hydrolysis reaction of the RNA substrate cannot be detected by this method due to the destruction of Trp residues upon prolonged irradiation at the wavelength of fluorescence excitation (photobleaching).

To calculate the observed rate constants, $k_{\text {obs }}$, the kinetic curves were approximated by equation (1). Considering that at the initial stage of the interaction of APE1 with substrates, an enzyme-substrate complex is formed, and this reaction is reversible, to calculate $k_{\text {obs }}$, we used equation (2), which is valid under the condition of an excess of one of the reaction components. Although this was not always feasible in our experiments, the dependence of $k_{\text {obs }}$ on the substrate concentration was linear (Fig. 8b), which corresponded to a one-stage binding mechanism and allowed calculate of the rate constants of the formation and decomposition of the enzyme-substrate complex (APE1 - HP1) using equation (2), where $k_{1}=5.4 \pm$ $0.7 \mu \mathrm{M}^{-1} \mathrm{~s}^{-1}, k_{-1}=23.6 \pm 1.9 \mathrm{~s}^{-1}$. In this case, the $K_{\mathrm{d}}$ value is $4.7 \pm 1.1 \mu \mathrm{M}$. This value is slightly higher than the value measured by the thermophoresis method (see Fig. 7b), however, given the fundamental difference in the methods and reaction conditions used to obtain the $K_{\mathrm{d}}$ values, such a discrepancy can be considered satisfactory.

We used model RNA substrates containing the fluorescent bases 2-aminopurine $(\mathrm{aPu})$ and pyrrolocytosine $\left(\mathrm{C}^{\mathrm{Py}}\right)$ in different positions of the hairpin (Table 1 , Fig. 8c). The fluorescence intensity of aPu and $C^{\text {Py }}$ depends on the hydrophilicity of the environment [36-39]; therefore, observing the change in their fluorescence intensity, one can estimate the magnitude of conformational transformations of the RNA substrate.

Based on these results, we can proposed that the aPu residue is insensitive to the processes occurring during the complex formation of enzyme with an RNA substrate, while for $\mathrm{C}^{\mathrm{Py}}$ an increase in the fluorescence intensity was recorded in the initial region of the kinetic curves (up to $10 \mathrm{~s}$ ), which can reflect the process of the enzyme-substrate complex formation.

\section{CONCLUSIONS}

Thus, we performed a comparative analysis of the AP endonuclease and endoribonuclease activities of 
(a)

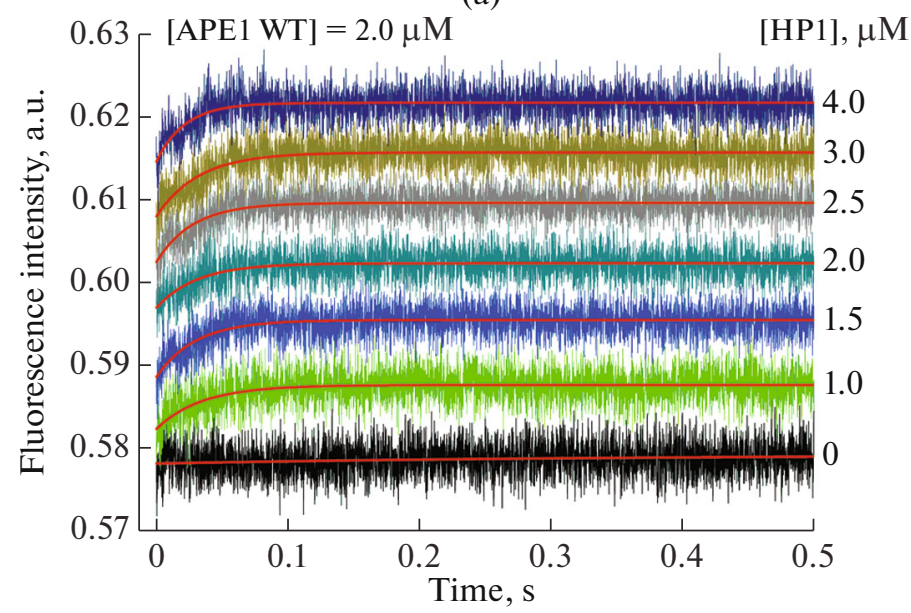

(c) (b)

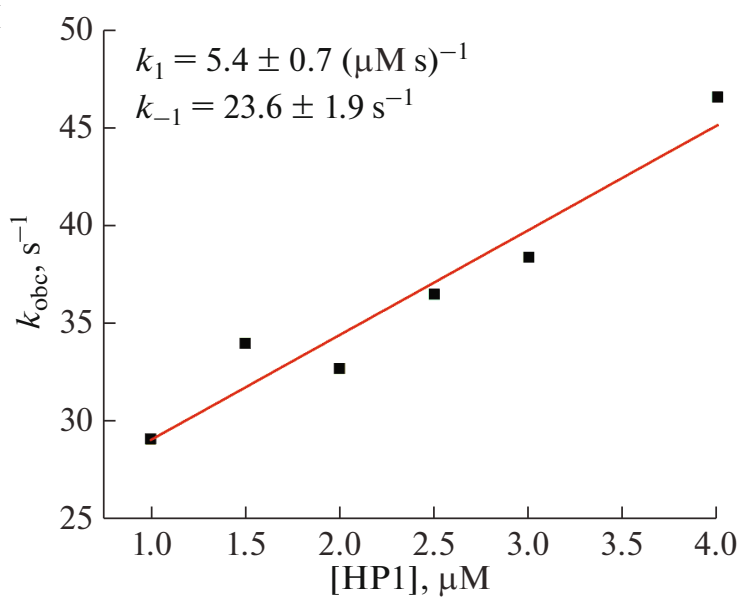

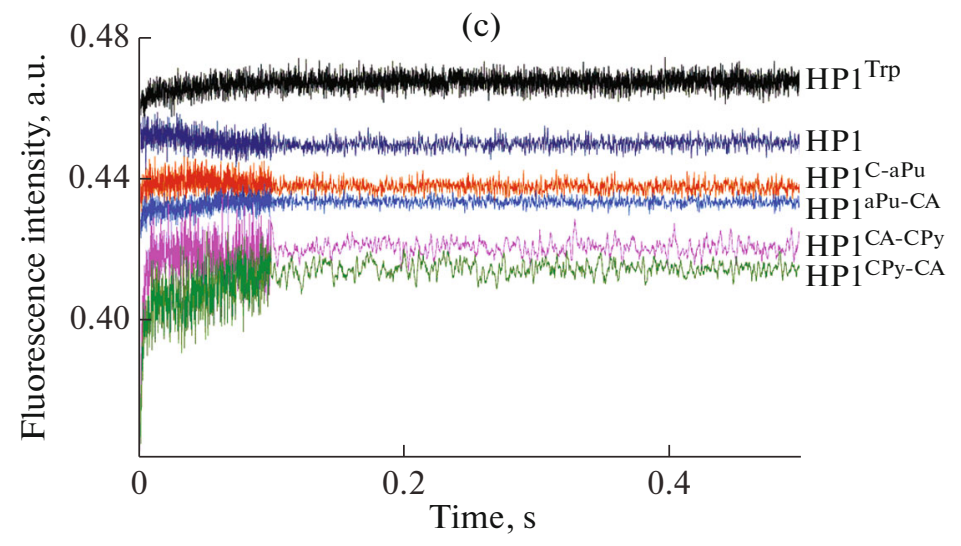

Fig. 8. Kinetics of interaction of wild-type APE1 with RNA substrates. (a) Changes in the intensity of fluorescence of Trp residues characterizing the formation of the enzyme-substrate complex. (b) Dependence of the observed rate constant $\left(k_{\text {obs }}\right)$ on the concentration of the RNA substrate HP1. (c) Changes in the fluorescence intensity of the aPu and $\mathrm{C}^{\mathrm{Py}}$ residues and FRET signal characterizing conformational transformations of the RNA substrate.

wild-type human apurinic/apyrimidinic endonuclease APE1 and eight mutant forms containing substitutions of amino acid residues involving in the active and substrate-binding sites of the enzyme. Interaction of APE1 with RNA substrates in the presence of $\mathrm{Ca}^{2+}$ ions, as well as in the absence of metal ions, resulted in the formation of the endoribonuclease reaction products, which indicates a metal-independent catalytic mechanism of hydrolysis of the phosphodiester bond in RNA substrates. In the presence of $\mathrm{Mg}^{2+}$ ions, both endoribonuclease and 3'-5'-exonuclease reactions proceeded. These two types of enzymatic activity are associated with different catalytic mechanisms. Thus, the replacement of the amino acid residues Asn212, Asp210, and Tyr171 leads to the loss of the AP endonuclease and 3'-5'-exonuclease activities with retention of the endoribonuclease activity, from which it can be concluded that APE1 utilizes an alternative mechanism of catalysis with respect to hydrolysis of the phosphodiester bond in RNA compared to DNA substrates. It was found that the substitutions T268D and M270A lead to a loss of specificity of the enzyme for the pyrimidine-purine sequence, and the mutations Arg 177 and Arg 181 insignificantly affect the activity of the enzyme. The D308A substitution was shown to lead to a decrease in the endoribonuclease activity of the enzyme, apparently due to the loss of contacts with the catalytically significant His309 residue.

\section{FUNDING}

The experimental work was supported by the Russian Science Foundation (project no. 19-74-10034) and partially supported by budgetary funding to ensure routine maintenance on the equipment No. AAAA-A17-117020210022-4.

\section{COMPLIANCE WITH ETHICAL STANDARDS}

The authors declare that they have no conflicts of interests.

The article contains no studies involving animals or humans as subjects of the study. 


\section{REFERENCES}

1. Gros L., Ishchenko A.A., Ide H., Elder R.H., Saparbaev M.K. 2004. The major human AP endonuclease (Ape1) is involved in the nucleotide incision repair pathway. Nucleic Acids Res. 32, 73-81.

2. Chen D.S., Herman T., Demple B. 1991. Two distinct human DNA diesterases that hydrolyze 3'-blocking deoxyribose fragments from oxidized DNA. Nucleic Acids Res. 19, 5907-5914.

3. Chou K.-M., Cheng Y.-C. 2003. The exonuclease activity of human apurinic/apyrimidinic endonuclease (APE1). Biochemical properties and inhibition by the natural dinucleotide $\mathrm{Gp}_{4}$ G. J. Biol. Chem. 278, 1828918296.

4. Kuznetsova A.A., Fedorova O.S., Kuznetsov N.A. 2018. Kinetic features of 3'-5' exonuclease activity of human AP-endonuclease APE1. Molecules. 23 (9), 2101.

5. Li M., Wilson 3rd D.M. 2014. Human apurinic/apyrimidinic endonuclease 1. Antioxid. Redox Signal. 20, 678-707.

6. Barzilay G., Hickson I.D. 1995. Structure and function of apurinic/apyrimidinic endonucleases. Bioessays. 17, 713-719.

7. Berquist B.R., McNeill D.R., Wilson D.M. 3rd. 2008. Characterization of abasic endonuclease activity of human Ape1 on alternative substrates, as well as effects of ATP and sequence context on AP site incision. J. Mol. Biol. 379, 17-27.

8. Barnes T., Kim W.C., Mantha A.K., Kim S.E., Izumi T., Mitra S., Lee C.H. 2009. Identification of apurinic/ apyrimidinic endonuclease 1 (APE1) as the endoribonuclease that cleaves $c$-myc mRNA. Nucleic Acids Res. 37, 3946-3958.

9. Kim S.E., Gorrell A., Rader S.D., Lee C.H. 2010. Endoribonuclease activity of human apurinic/apyrimidinic endonuclease 1 revealed by a real-time fluorometric assay. Anal. Biochem. 398, 69-75.

10. Kim W.C., King D., Lee C.H. 2010. RNA-cleaving properties of human apurinic/apyrimidinic endonuclease 1 (APE1). Int. J. Biochem. Mol. Biol. 1, 12-25.

11. Mol C.D., Izumi T., Mitra S., Tainer J.A. 2000. DNAbound structures and mutants reveal abasic DNA binding by APE1 DNA repair and coordination. Nature. 403, 451-456.

12. Barzilay G., Walker L.J., Robson C.N., Hickson I.D. 1995. Site-directed mutagenesis of the human DNA repair enzyme HAP1: Identification of residues important for AP endonuclease and RNase $\mathrm{H}$ activity. Nucleic Acids Res. 23, 1544-1550.

13. Tsutakawa S.E., Shin D.S., Mol C.D., Izumi T., Arvai A.S., Mantha A.K., Szczesny B., Ivanov I.N., Hosfield D.J., Maiti B., Pique M.E., Frankel K.A., Hitomi K., Cunningham R.P., Mitra S., Tainer J.A. 2013. Conserved structural chemistry for incision activity in structurally non-homologous apurinic/apyrimidinic endonuclease APE1 and endonuclease IV DNA repair enzymes. J. Biol. Chem. 288, 8445-8455.

14. Miroshnikova A.D., Kuznetsova A.A., Vorobjev Y.N., Kuznetsov N.A., Fedorova O.S. 2016. Effects of monoand divalent metal ions on DNA binding and catalysis of human apurinic/apyrimidinic endonuclease 1. Mol. Biosyst. 12, 1527.
15. Jen-Jacobson L., Engler L.E., Jacobson L.A. 2000. Structural and thermodynamic strategies for site-specific DNA binding proteins. Structure. 8, 1015-1023.

16. Kim W.C., Berquist B.R., Chohan M., Uy C., Wilson D.M., Lee C.H. 2011. Characterization of the endoribonuclease active site of human apurinic/apyrimidinic endonuclease 1. J. Mol. Biol. 411, 960-971.

17. Alekseeva I.V., Kuznetsova A.A., Bakman A.S., Fedorova O.S., Kuznetsov N.A. 2020. The role of active-site amino acid residues in the cleavage of DNA and RNA substrates by human apurinic/apyrimidinic endonuclease APE1. Biochim. Biophys. Acta Gen. Subj. 1864, 129718.

18. Kuzmic P. 1996. Program DYNAFIT for the analysis of enzyme kinetic data: Application to HIV proteinase. Anal. Biochem. 237, 260-273.

19. Masuda Y., Bennett R.A., Demple B. 1998. Rapid dissociation of human apurinic endonuclease (Ape1) from incised DNA induced by magnesium. J. Biol. Chem. 273, 30360-30365.

20. Rothwell D.G., Hang B., Gorman M.A., Freemont P.S., Singer B., Hickson I.D. 2000. Substitution of Asp-210 in HAP1 (APE/Ref-1) eliminates endonuclease activity but stabilizes substrate binding. Nucleic Acids Res. 28, 2207-2213.

21. Mundle S.T., Fattal M.H., Melo L.F., Coriolan J.D., O'Regan N.E., Strauss P.R. 2004. Novel role of tyrosine in catalysis by human AP endonuclease 1. DNARepair (Amst.). 3, 1447-1455.

22. Freudenthal B.D., Beard W.A., Cuneo M.J., Dyrkheeva N.S., Wilson S.H. 2015. Capturing snapshots of APE1 processing DNA damage. Nat. Struct. Mol. Biol. 22, 924-931.

23. Redrejo-Rodriguez M., Vigouroux A., Mursalimov A., Grin I., Alili D., Koshenov Z., Akishev Z., Maksimenko A., Bissenbaev A.K., Matkarimov B.T., Saparbaev M., Ishchenko A.A., Moréra S. 2016. Structural comparison of AP endonucleases from the exonuclease III family reveals new amino acid residues in human AP endonuclease 1 that are involved in incision of damaged DNA. Biochimie. 128, 20-33.

24. Kuznetsova A.A., Novopashina D.S., Fedorova O.S., Kuznetsov N.A. 2020. Effect of substrate structure and metal ions on the efficiency of undamaged RNA hydrolysis by human apurinic/apyrimidinic endonuclease APE1. Acta Naturae. 12, 74-85.

25. Gorman M.A., Morera S., Rothwell D.G., de La Fortelle E., Mol C.D., Tainer J.A., Hickson I.D., Freemont P.S. 1997. The crystal structure of the human DNA repair endonuclease HAP1 suggests the recognition of extra-helical deoxyribose at DNA abasic sites. EMBO J. 16, 6548-6558.

26. Beernink P.T., Segelke B.W., Hadi M.Z., Erzberger J.P., Wilson D.M., Rupp B. 2001. Two divalent metal ions in the active site of a new crystal form of human apurinic/apyrimidinic endonuclease, Ape 1: Implications for the catalytic mechanism. J. Mol. Biol. 307, 1023-1034.

27. Manvilla B.A., Pozharski E., Toth E.A., Drohat A.C. 2013. Structure of human apurinic/apyrimidinic endonuclease 1 with the essential $\mathrm{Mg}^{2+}$ cofactor. Acta Crystallogr. D: Biol. Crystallogr. 69, 2555-2562. 
28. Lipton A.S., Heck R.W., Primak S., McNeill D.R., Wilson D.M., Ellis P.D. 2008. Characterization of $\mathrm{Mg}^{2+}$ binding to the DNA repair protein apurinic/apyrimidic endonuclease 1 via solid-state $25 \mathrm{Mg}$ NMR spectroscopy. J. Am. Chem. Soc. 130, 9332-9341.

29. Oezguen N., Schein C.H., Peddi S.R., Power T.D., Izumi T., Braun W. 2007. A 'moving metal mechanism' for substrate cleavage by the DNA repair endonuclease APE-1. Proteins. 68, 313-323.

30. Erzberger J.P., Wilson D.M. 1999. The role of $\mathrm{Mg}^{2+}$ and specific amino acid residues in the catalytic reaction of the major human abasic endonuclease: New insights from EDTA-resistant incision of acyclic abasic site analogs and site-directed mutagenesis. J. Mol. Biol. 290, 447-457.

31. He H., Chen Q., Georgiadis M.M. 2014. High-resolution crystal structures reveal plasticity in the metal binding site of apurinic/apyrimidinic endonuclease I. Biochemistry. 53, 6520-6529.

32. Bulygin A.A., Kuznetsova A.A., Vorobjev Y.N., Fedorova O.S., Kuznetsov N.A. 2020. The role of activesite plasticity in damaged-nucleotide recognition by human apurinic/apyrimidinic endonuclease APE1. Molecules. 25, 3940.

33. Miroshnikova A.D., Kuznetsova A.A., Kuznetsov N.A., Fedorova O.S. 2016. Thetmodynamics of conforma- tional transitions in human AP endonuclease APE1 upon interaction with DNA. Acta Naturae. 8, 103-110.

34. Maher R.L., Bloom L.B. 2007. Pre-steady-state kinetic characterization of the AP endonuclease activity of human AP endonuclease 1. J. Biol. Chem. 282, 3057730585.

35. Timofeyeva N.A., Fedorova O.S. 2016. A kinetic mechanism of repair of DNA containing alpha-anomeric deoxyadenosine by human apurinic/apyrimidinic endonuclease 1. Mol. Biosyst. 12, 3435-3446.

36. Jean J.M., Hall K.B. 2001. 2-Aminopurine fluorescence quenching and lifetimes: Role of base stacking. Proc. Natl. Acad. Sci. U. S. A. 98, 37-41.

37. Rachofsky E.L., Osman R., Ross J.B. 2001. Probing structure and dynamics of DNA with 2-aminopurine: Effects of local environment on fluorescence. Biochemistry. 40, 946-956.

38. Rist M.J., Marino J.P. 2002. Fluorescent nucleotide base analogs as probes of nucleic acid structure, dynamics and interactions. Curr. Org. Chem. 6, 775-793.

39. Berry D.A., Jung K.Y., Wise D.S., Sercel A.D., Pearson W.H., Mackie H., Randolph J.B., Somers R.L. 2004. Pyrrolo-dC and pyrrolo-C: fluorescent analogs of cytidine and 2'-deoxycytidine for the study of oligonucleotides. Tetrahedron Lett. 45, 2457-2461.

Translated by N. Onishchenko 